\title{
Average Air Temperature Inside a Room With a Semitransparent Wall With a Solar Control Film: Effect of The Emissivity
}

\author{
J. Xamán ${ }^{1 *}$, G. Álvarez ${ }^{1}$, Y. Chávez ${ }^{1}$, J.O. Aguilar ${ }^{2}$, J. Arce $^{1}$ \\ ${ }^{1}$ Centro Nacional de Investigación y Desarrollo Tecnológico. \\ CENIDET-DGEST-SEP Prol. Av. Palmira S/N. Col. Palmira. 44 \\ Cuernavaca, Morelos, CP 62490, México. \\ * jxaman@cenidet.edu.mx, \\ 2 Universidad de Quintana Roo. UQROO \\ Blvd. Bahía S/N, Esq. Ign. Comonfort, Col. del Bosque, \\ Chetumal, Quintana Roo, C.P. 77019, México.
}

\begin{abstract}
In this paper a theoretical study on conjugated heat transfer (natural convection, radiation and conduction) in a square room (cavity) with turbulent flow is presented, taking into account variation on the opaque wall emissivity. The room is formed by an isothermal vertical wall, two adiabatic horizontal walls and a semitransparent wall with and without a control solar radiation film. The governing equations for turbulent flow in $2 \mathrm{D}$ were solved using a finite volume formulation and $k-\varepsilon$ turbulent model. Results for an isothermal wall at $21^{\circ} \mathrm{C}$ and an external temperature of $35^{\circ} \mathrm{C}$ are presented. The size of the room is $4.0 \mathrm{~m}$ length and height and the solar radiation falling directly on the semitransparent wall was $750 \mathrm{~W} / \mathrm{m}^{2}$ (AM2). The emissivity of the opaque walls was varied between $0.1 \leq \varepsilon^{*} \leq 1.0$. Results show that, based on the air average temperature and the effective heat flux inside the room, the solar control film under study was advantageous for energy saving purposes, for emissivity values of $\varepsilon^{*} \leq 0.46$. A correlation on this system for the heat transfer as a function of the emissivities was determined.
\end{abstract}

Keywords: Conjugate heat transfer, $k-\varepsilon$ turbulent model, emissivity.

\section{RESUMEN}

En este artículo se presenta un estudio teórico de la transferencia de calor conjugada (convección natural, conducción y radiación) en flujo turbulento de una habitación cuadrada (cavidad), considerando la variación de la emisividad en la pared opaca. La habitación consiste de una pared vertical isotérmica, dos paredes horizontales adiabáticas y una pared semitransparente con y sin película de control de radiación solar. Las ecuaciones gobernantes para flujo turbulento en 2 dimensiones se resolvieron usando una formulación de volumen finito y el modelo de turbulencia $k-\varepsilon$. Se presentan los resultados para una pared isotérmica a $21^{\circ} \mathrm{C}$ y una temperatura exterior de $35^{\circ} \mathrm{C}$. Las dimensiones de la habitación son $4 \mathrm{~m}$ de longitud y altura y la radiación solar que cae directamente sobre la pared semitransparente es de $750 \mathrm{~W} / \mathrm{m}^{2}$ (AM2). La emisividad de las paredes opacas fue variando entre 0.1 $\leq \varepsilon^{*} \leq 1.0$. Los resultados muestran que, con base en la temperatura ambiente del aire y el flujo de calor efectivo dentro de la habitación, la película de control solar bajo estudio resultó ser desventajosa para propósitos de ahorro de energía, para valores de emisividad de $\varepsilon^{*} \leq 0.46$. Se determinó para el sistema una correlación para la transferencia de calor en función de las emisividades.

\section{NOMENCLATURE}

$C_{p}$ specific heat, $\mathrm{J} \mathrm{kg}^{-1} \mathrm{~K}^{-1}$

$d F_{d A_{j}-d A_{k}}$ view factor between elements $j-k$

$g^{*}$ gravitational acceleration, $9.81 \mathrm{~m} \mathrm{~s}^{-2}$

$\mathrm{G}$ solar radiation, $\mathrm{W} \mathrm{m}^{-2}$.

$G_{k}$ buoyancy production/destruction of kinetic energy

$h_{\text {ext }}$ convective heat transfer coefficient at the outside glass wall, $\mathrm{Wm}^{-2} \mathrm{~K}^{-1}$

$H$ height of the cavity, $\mathrm{m}$

$L$ length of the cavity, $m$

$L_{g}$ thickness of the glass, $m$
$P$ pressure, $\mathrm{Pa}$

$P_{K}$ turbulence kinetic energy production

$Q$ heat flux, $W \mathrm{~m}^{-2}$

$s_{g}$ extinction coefficient, $\mathrm{m}^{-1}$

$T$ temperature, $\mathrm{K}$

$T_{2}$ cold wall temperature, $\mathrm{K}$

$T_{\text {g-average }}$ inside average temperature of the glass wall, $\mathrm{K}$

$T_{0}$ reference temperature $\left[\left(T_{\text {g-average }}+T_{2}\right) / 2\right], \mathrm{K}$

$u, v$ dimensional horizontal and vertical velocities, $\mathrm{m} \mathrm{s}^{-1}$

$x, y$ dimensional coordinates, $\mathrm{m}$ 


\section{Greek symbols}

$\alpha^{*}$ absorptivity

$\beta$ thermal expansion coefficient, $\mathrm{K}^{-1}$

$\varepsilon$ rate of dissipation of $\kappa, \mathrm{m}^{2} \mathrm{~s}^{-3}$

$\varepsilon^{*}$ emissivity

$\kappa$ turbulence kinetic energy, $\mathrm{m}^{2} \mathrm{~s}^{-2}$

$\lambda$ thermal conductivity, $\mathrm{W} \mathrm{m}^{-1} \mathrm{~K}^{-1}$

$\mu$ dynamic viscosity, $\mathrm{kg} \mathrm{m}^{-1} \mathrm{~s}^{-1}$

$\mu_{t}$ turbulent viscosity, $\mathrm{kg} \mathrm{m}^{-1} \mathrm{~s}^{-1}$

$\rho$ density, $\mathrm{kg} \mathrm{m}^{-3}$

$\rho$ reflectivity

$\sigma$ Stefan-Boltzman constant, $5.670 \times 10^{-8} \mathrm{~W} \mathrm{~m}^{-2} \mathrm{~K}^{-4}$

$\sigma_{k}$ Prandtl number for $k$

$\sigma_{\varepsilon}$ Prandtl number for $\varepsilon$

$\tau^{\star}$ transmissivity

\section{Subscripts}

a air

ext ambient

cond conductive

conv convective

$f$ film

$g$ glass wall

int inside

out outside

rad radiative

total total quantities

\section{Introduction}

In an effort to reduce economic costs generated by electricity consumption used by air conditioning systems in buildings and rooms, diverse alternatives for passive acclimatization have been developed. One of these alternatives has to do with the use of solar control films applied on the windows glass, which are commonly used on many modern buildings. The goal when using control solar films on the windows glass is to reduce heat gains inside the building, located climates [1]. For mathematical simulations, rooms are often modeled as square cavities. Several studies on cavities with different configurations and boundary conditions have been carried out. Nevertheless, this work has to do with studies on conjugated heat transfer in cavities with a semitransparent wall. Previous studies have analyzed the effect of radiative exchange on natural convection inside a cavity and showed that the effect is significant and should not be neglected [2-4]. Few studies have considered the effect of radiative exchange when a semitransparent wall is placed in the cavity. Behnia et al. [5] consider a cavity with one glass sheet wall and presented numerical results for a variety of Rayleigh numbers in the range $10^{4}<R a<3 \times 10^{5}$. The authors concluded that, in general terms, the external convection weakens the internal circulation, radiation strengthens it, and in combination the overall effect is a strengthening of the internal circulation. Kwon et al. [21] presented a numerical study of combined laminar natural convection and radiation in a rectangular enclosure with a transparent window. Their results show that temperature distributions of adiabatic walls increase with the transmittance of the transparent window, however, the effects of solar radiation are higher than those of surface radiation and pure natural convection. Álvarez and Estrada [6] published results of a transient computational model for combined laminar natural convection, conduction and radiation in a square cavity. The cavity is modeled with a vertical glass wall with film coating. Results show that there is a diminished convective regime due to the influence of the radiative exchange. The authors show that the total energy transferred through the glass/solar control coating system is lower than the case that uses just clear glass. Xamán and Álvarez [7] determined the influence of a semitransparent glazing, with and without a SnS- $\mathrm{Cu}_{\mathrm{x}} \mathrm{S}$ solar control coating, on turbulent natural convection in a square cavity where the effects of surface thermal radiation were neglected. Results show that the direct solar energy transmittance of the semitransparent glazing with a film coating was much lower than the case without a solar control coating and therefore, the total heat gain through the glazing with the solar control coating would be lower than the one without the solar control coating. Subsequently, Xamán et al. [8] studied the conjugate heat transfer (laminar and turbulent natural convection, surface thermal radiation and conduction) in a square cavity with a glass wall. The Rayleigh number was varied in the range of $10^{3} \leq R a \leq 10^{12}$. Results showed that the flow pattern was not symmetric due to the combined effect of the non-isothermal glass wall and radiative exchange inside the cavity. As well, the surface thermal radiation was neglected, a significant under estimation of the total heat transfer was found. The authors presented a correlation for the total Nusselt number for both laminar and turbulent flow considering conjugate heat transfer. Recently, Xamán et al. [9] presented a detailed study of fluid 
flow and heat transfer caused by turbulent natural convection and surface thermal radiation in a square cavity with a semitransparent wall with (case A), and without (case B), a solar control film. The objective of the study was: to obtain the thermal parameters for cases approaching real sized rooms and to evaluate the thermal effect of using a semitransparent wall with, and without, a solar control film on the airflow in the cavity. A Rayleigh number range from $10^{9}$ to $10^{12}$ was chosen for the heat transfer study in a square cavity. Results showed that by using the solar control film coating on the semitransparent wall, the total heat flux was reduced from 646.24 to $331.44 \mathrm{~W} / \mathrm{m}^{2}$, even though the temperatures of the film coating on the semitransparent wall (case A) were higher than the ones obtained without solar control film (case B), also the air temperature values in the cavity were higher for case $A$ than for case $B$.

According to previous studies $[8,10]$ the use of a $\mathrm{SnS}-\mathrm{Cu}_{\mathrm{x}} \mathrm{S}$ film results in a lower heat gain inside the cavity, but air temperatures are higher than the case without the film. The authors believed that the emissivity value of the opaque walls had an influence on the air temperature and that, there might be emissivity values for which the average air temperature inside the cavity has an opposite behavior to that as describe above.

This study shall extend the previous work carried out by Xaman et al [9], by taking into account different emissivity values for the opaque walls (gray-diffuse surfaces) of a square cavity with a semitransparent wall, for the cases with and without a solar control film. This study aims to find the range for which the emissivity value of the opaque walls gives a lower heat gain and corresponding air temperatures inside the cavity, as compared to those obtained when not using a solar control film.

\section{Physical model and assumptions}

The heat transfer and fluid flow in a twodimensional closed square cavity was considered. Assuming that the dimension in $z$ direction is much longer than the other two, then a two dimensional assumption can be applied. (Figure 1). The thermal fluid was assumed to be air in turbulent regime, initially at rest and with a uniform temperature. The cavity is formed by two horizontal adiabatic walls, one vertical isothermal wall and one semitransparent wall (a glass sheet) consisting of glass and a solar control film adhered to the inside surface. The left surface of the cavity is an isothermal opaque wall at $21^{\circ} \mathrm{C}\left(T_{2}=294 \mathrm{~K}\right)$; the top and bottom horizontal surfaces were considered adiabatic. On the semitransparent wall an incoming normal uniform and constant solar radiation flux $\left(750 \mathrm{~W} / \mathrm{m}^{2}\right)$ was considered and two dimensional heat transfer by conduction was taken into account. The semitransparent wall transmits, reflects and absorbs normal solar radiation flux. Absorbed solar radiation flux increases the glazing temperature and it is transferred by conduction to the inside and outside of the cavity. The semitransparent wall, as well as the opaque walls is considered gray, diffusive, reflective surface and an emitter of thermal radiation. The thermal fluid was considered radiatively nonparticipating. The thermophysical properties of the air were assumed constant except for the density in the buoyancy force term in the momentum equations, according to the Boussinesq approximation. The optical properties considered were the integrated solar spectrum values. The film solar control coating selected was $\mathrm{SnS}-\mathrm{Cu}_{\mathrm{x}} \mathrm{S}$.

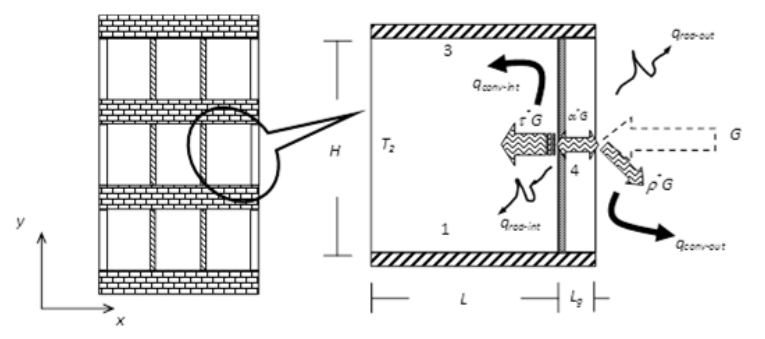

Figure 1. Physical model of the square cavity with a semitransparent wall

\section{Mathematical model}

\subsection{Turbulent natural convection model}

The turbulent natural convection considered in the square cavity with a semitransparent wall is described mathematically by the Reynolds averaged Navier Stokes (RANS) equations. The RANS equations for mass, momentum and energy conservation are expressed in tensor form as: 


$$
\begin{gathered}
\frac{\partial\left(\rho u_{i}\right)}{\partial x_{i}}=0 \\
\frac{\partial\left(\rho u_{j} u_{i}\right)}{\partial x_{j}}=-\frac{\partial P}{\partial x_{i}}+\frac{\partial}{\partial x_{j}}\left(\mu \frac{\partial u_{i}}{\partial x_{j}}\right. \\
\frac{\partial\left(\rho u_{i} T\right)}{\partial x_{i}}=\frac{\partial}{\partial x_{i}}\left(\frac{\lambda}{C_{p}} \frac{\partial T}{\partial x_{i}}-\rho \overline{u_{i}^{\prime} T^{\prime}}\right)
\end{gathered}
$$$$
\frac{\partial\left(\rho u_{j} u_{i}\right)}{\partial x_{j}}=-\frac{\partial P}{\partial x_{i}}+\frac{\partial}{\partial x_{j}}\left(\mu \frac{\partial u_{i}}{\partial x_{j}}-\rho \overline{u_{i}^{\prime} u_{j}^{\prime}}\right)-\rho \beta\left(T-T_{0}\right) g_{i}^{*} \frac{\partial\left(\rho u_{i} \varepsilon\right)}{\partial x_{i}}=\frac{\partial}{\partial x_{i}}\left[\left(\mu+\frac{\mu_{t}}{\sigma_{\varepsilon}}\right) \frac{\partial \varepsilon}{\partial x_{i}}\right]+\left[C_{1 \varepsilon}\left(P_{k}+C_{3 \varepsilon} G_{\kappa}\right)-C_{2 \varepsilon} \rho \varepsilon\right] \frac{\varepsilon}{k}
$$

$$
\frac{\partial\left(\rho u_{i} k\right)}{\partial x_{i}}=\frac{\partial}{\partial x_{i}}\left[\left(\mu+\frac{\mu_{t}}{\sigma_{k}}\right) \frac{\partial k}{\partial x_{i}}\right]+P_{k}+G_{k}-\rho \varepsilon
$$

The above system of equations is not complete because of the presence of the unknown Reynolds stress tensor $\left(\rho \overline{u_{i}^{\prime} u_{j}^{\prime}}\right)$ in the momentum equation and the turbulent heat vector $\left(\rho \overline{u_{i}^{\prime} T^{\prime}}\right)$ in the energy equation. In the Eddy Viscosity Model (EVM) the Reynolds stress tensor is modeled through the Boussinesq hypothesis as [11-12]:

$$
\rho \overline{u_{i}^{\prime} u_{j}^{\prime}}=-\mu_{t}\left(\frac{\partial u_{i}}{\partial x_{j}}+\frac{\partial u_{j}}{\partial x_{i}}\right)+\frac{2}{3} \rho k \delta_{i j}
$$

The High Reynolds Number model (HRN) establishes that the turbulent viscosity $\left(\mu_{t}\right)$ can be obtained as:

$$
\mu_{t}=C_{\mu} \frac{\rho k^{2}}{\varepsilon}
$$

where $C_{\mu}$ is a constant. The turbulent heat vector is modeled as follow:

$$
\rho \overline{u_{i}^{\prime} T^{\prime}}=-\frac{\mu_{t}}{\sigma_{T}} \frac{\partial T}{\partial x_{i}}
$$

where $\sigma_{T}$ is the turbulent Prandtl number and $\delta_{i j}$ is the Kronecker delta. The turbulent viscosity can be related with the turbulent kinetic energy $(\kappa)$ and the turbulent dissipation of kinetic energy $(\varepsilon)$ through the empirical equation of Kolmorogov-Prandtl [18]. The turbulent kinetic energy and the turbulent dissipation of kinetic energy can be obtained using its corresponding transport equation: where, $P_{k}$ and $G_{k}$ are the production of turbulent kinetic energy by shearing and the generation/destruction by buoyancy.

The mathematical velocity boundary conditions on the walls are zero and the temperature boundary conditions are set as: adiabatic horizontal walls (top and bottom), the left vertical wall is isotherm and heat transfer by conduction is considered at the semitransparent wall (right wall), that is

Bottom wall:

$$
q_{\text {conv-1 }}+q_{\text {rad }-1}=0
$$

Isothermal vertical wall:

$$
T(0, y)=T_{2}
$$

Upper wall:

$$
q_{\text {conv-3 }}+q_{\text {rad }-3}=0
$$

Semitransparent vertical wall:

$$
q_{a b s}+q_{\text {cond }-g-4}=q_{c o n v-4}+q_{\text {rad }-4}
$$

Where $q_{\text {conv-1 }}, q_{\text {conv-3 }}$ and $q_{c o n v-4}$ are the convective heat transfer fluxes from the inside surface to the adjacent fluid on walls 1,3 and 4 respectively. The terms $q_{\text {rad-1 }}, q_{\text {rad }-3}$ and $q_{\text {rad }-4}$ are the net radiative heat transfer fluxes at walls 1 , 3 and 4 . The term $q_{a b s}$ is the thermal energy that is absorbed by the solar control film of the glazing. Finally, $q_{\text {cond-g-4 }}$ is the heat flux by heat conduction through the semitransparent wall.

The boundary conditions and coefficient values for $k-\varepsilon$ turbulence model are: $k_{w}=0.0, \varepsilon_{w}=\infty, C_{\mu}=$ $0.09, C_{1 \varepsilon}=1.44, C_{2 \varepsilon}=1.92, \sigma_{k}=1.0, \sigma_{\varepsilon}=1.3$ and $C_{3 \varepsilon}=\tanh |v / u|[10]$. 


\subsection{Conduction model of the semitransparent wall}

In order to obtain the temperature profile inside the semitransparent wall formed by glass $\left(L_{g}=6 \mathrm{~mm}\right)$ with a thin solar control film coating, a differential energy balance was carried out. The model solution is used to determine the conductive heat flux of wall $4 \quad\left(q_{\text {cond }-g-4}\right)$. The heat transfer conduction equation for the differential element of the semitransparent wall is given by:

$$
\frac{\partial}{\partial x_{i}}\left(\frac{\lambda_{g}}{C_{p g}} \frac{\partial T_{g}}{\partial x_{i}}\right)+\frac{1}{C_{p g}} \frac{d \Theta}{d x}=0
$$

where $\Theta$ is the attenuation energy function by absorption and scattering, which depends of the extinction coefficient $\left(s_{g}\right)$ as follows [19]:

$$
\Theta(x)=G \exp \left[-S_{g}\left(L_{g}-x\right)\right]
$$

The outside boundary condition for the semitransparent wall at $\left(x=L+L_{g}\right)$ can be expressed as:

$$
-\lambda_{g} \frac{\partial T_{g}}{\partial x}=h_{e x t}\left[T_{g}-T_{a m b}\right]+\sigma \varepsilon_{g}^{*}\left[T_{g}^{4}-T_{a m b}^{4}\right]
$$

Where, $T_{a m b}$ is the outside ambient temperature. The film thickness $(\approx 6 \mu \mathrm{m})$ was considered negligible with regard to the glass thickness (6 $\mathrm{mm})$. In order to obtain the film temperature $\left(T_{f}\right)$ at $(x=L)$, the following energy balance at the film was carried out:

$$
\alpha_{f}^{*} \tau_{g}^{*} G=-\lambda_{g} \frac{\partial T_{g}}{\partial x}+\lambda_{a} \frac{\partial T}{\partial x}+q_{r a d-4}
$$

where $T_{f}=T_{g}(0, y)$

The boundary conditions are adiabatic for the horizontal walls.

\subsection{Surface thermal radiation model}

The net radiative method was used to calculate the resulting heat fluxes from the radiative exchange [19]. The thermal radiative exchange between the cavity surfaces is shown in Figure 2, using two differential areas on surfaces 1 and 2 . The cavity surfaces are assumed opaque and diffuse except the vertical right wall which is a semitransparent wall. The radiative heat transfer from a surface is defined as the difference between the outgoing thermal radiation (radiosity) and the incoming thermal radiation (irradiance). Therefore, making an energy balance over the differential element $d A_{j}$, located in $r_{j}$ position on wall 1 (Figure 2), we can obtain the resulting heat radiative flux for wall 1 :

$$
q_{\text {rad }_{j}}\left(x_{j}\right)=q_{\text {out }}\left(x_{j}\right)-q_{\text {in }_{j}}\left(x_{j}\right)
$$

Where the radiosity is defined for a diffuse opaque surface as the sum of emitted energy and reflected energy, what can be formulated for the jth element as:

$$
q_{\text {out }{ }_{j}}\left(x_{j}\right)=\varepsilon_{j}^{*} \sigma T_{j}^{4}\left(x_{j}\right)+\rho_{j}^{*} q_{\text {in }}\left(x_{j}\right)
$$

The irradiance is defined as the sum of energy fractions outgoing from cavity surfaces differential elements that arrives to the analyzed surface. The irradiance mathematical formulation for a surface element $j$ on wall 1 is given by:

$$
q_{\text {in }_{j}}\left(x_{j}\right)=\sum_{k=1}^{m} \int_{A_{k}} q_{\text {out }_{k}}\left(x_{k}\right) d F_{d A_{j}-d A_{k}}
$$

Where the summation over the $k$ th surface element is to be taken for those elements over the boundary for which $j$ interacts radiatively. $d F_{d A_{j}-d A_{k}}$ is the corresponding differential view factor.

Similar equations can be derived for the remaining opaque cavity walls.

\section{Thermal parameters}

The average Nusselt number is a parameter used to quantify total heat transfer inside the cavity. The total heat transfer involves the contribution of the convective and radiative Nusselt numbers; thus, the total convective and radiative Nusselt numbers can be expressed as:

$$
N u_{\text {total }}=N u_{\text {conv }}+N u_{\text {rad }}
$$


where:

$$
\begin{aligned}
& N u_{\text {conv }}=\frac{-\lambda}{q_{\text {cond }}} \int_{0}^{H} \frac{\partial T}{\partial x} d y \\
& N u_{\text {rad }}=\frac{1}{q_{\text {cond }}} \int_{0}^{H} q_{\text {rad }-4} d y \\
& q_{\text {cond }}=\lambda\left(T_{4}-T_{2}\right) / L
\end{aligned}
$$

where $T_{4}$ is the average temperature on the inside surface of the semitransparent wall and $T_{2}$ as the temperature on the left wall (wall 2).

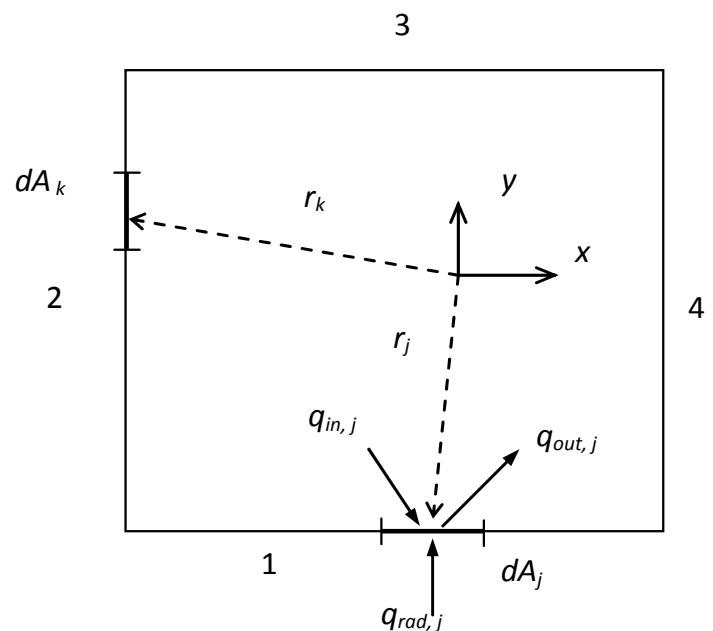

Figure 2. Radiative balances in differential areas

\section{Methodology for the numerical solution}

\subsection{Discretization}

The coupled elliptic partial differential equations of the convective and conductive model described above are discretized with the finite volume method [20]. The equations are integrated over elementary control volumes located around each node of a grid. The position of the nodes is calculated using a stretching function so that the nodes are closer to each other near the walls of the cavity. The velocity components are calculated at a staggered grid while the scalar variables are calculated at the main grid (not-staggered) (Figure 3 ). The convective terms are discretized applying the hybrid scheme and the diffusive terms with the central difference scheme. Coupling between the momentum and continuity equations is made with the SIMPLEC algorithm [11]. The algebraic equations system is solved by applying the line by line method (LBL) with alternating direction (ADI). Furthermore, under-relaxation is introduced using the false transient strategy. If the residual values of the different equations and the mass balance for every control volume are sufficiently low, overall convergence is obtained (typically $10^{-10}$ ). This convergence criterion assures an acceptable solution. A radiative balance at the walls is solved using an iterative approach in order to couple turbulent natural convection to surface thermal radiation effects at the boundaries. The view factors between the elements were determined by using the equations reported by Álvarez and Estrada [6].

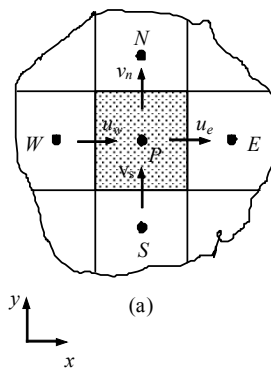

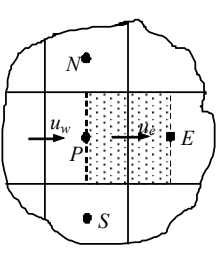

(b)

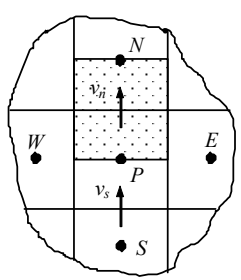

(c)
Figure 3. Cartesian grid showing placement of control volume boundaries: (a) control volume for a scalar variable $(P, T$, etc...), (b) control volume for horizontal velocity $u_{e}$ and (c) control volume for vertical velocity $v_{n}$.

The general procedure for the conjugate heat transfer in a cavity can be summarized in the following steps: 1) Initial guess values of all variables $(u, v, T, \ldots \varepsilon)$ in the cavity were given; 2$)$ Equations (17)-(19) were computed for each wall in order to get the local radiative heat flux on the walls $\left(q_{\text {rad }-1}, q_{\text {rad }-3}\right.$ and $\left.q_{\text {rad }-4}\right) ; 3$ ) The conductive model to obtain $q_{\text {cond-g-4 }}$ was solved; 4) The pressure-velocity $(u, v, p)$ were calculated by the SIMPLEC algorithm; 5) With the new calculated values of local radiative heat flux and velocity, the temperature $(T)$, the turbulent kinetic energy $(\kappa)$ and the turbulent dissipation of kinetic energy $(\varepsilon)$ field in the cavity were obtained; 6) A convergence criterion was applied; and, 7) the process was repeated iteratively until the convergence criterion was achieved. 
The accuracy of the numerical results was verified through numerous tests based on the grid size effect. Based on numerical calculations, the computational grid that gives grid independent solutions was $91 \times 81$ with a maximum deviation of $2 \%$ for the average Nusselt number. Therefore, a $91 \times 81$ grid was used for all cases herein considered. The discretization for the semitransparent wall $(6 \mathrm{~mm})$ was always 10 nodes in the horizontal direction for all the meshes.

\subsection{Verification of the numerical code}

The numerical code developed to solve this problem has been verified and validated using different problems from literature; comparisons have been reported on diverse publications by Xamán et al. [8-10, 16-17]. Among these comparisons is the verification and validation of the Benchmak problem for natural convection with turbulent flow in a square cavity reported by Henkes et al. [14] for numerical results, and Ampofo et al. [15] for experimental results. Besides, comparisons with numerical [16] and experimental [17] results, for tall cavities have been carried out, as well as verifications with the conjugated heat transfer problem (natural convection-surface thermal radiation). As a complement to this section comparison results with Velusamy et al. [3] for natural convection with turbulent flow and surface thermal radiation in a square cavity differentially heated is presented. Comparison of results was made with the following two cases: Case 1 (the walls have an emissivity equal to $0.9, T_{4}=328 \mathrm{~K}, T_{2}=318 \mathrm{~K}$ and $R a=10^{11}$ ) and Case 2 (the walls have an emissivity equal to $0.9, T_{4}=348 \mathrm{~K}, T_{2}=298 \mathrm{~K}$ and $R a=10^{11}$ ). The comparison of results is analyzed for both cases in terms of the average Nusselt numbers (convective (conv) and radiative $(\mathrm{rad})$ ) in the hot $(h)$ and cold (c) walls. The maximum and minimum observed differences for Case 1 are $3.14 \%$ for $N u_{c f}$ and 0.11 $\%$ for $N u_{h r}$ respectively. In Case 2, the maximum difference observed is $3.29 \%$ for $N u_{c f}$ and the minimum difference is $0.10 \%$ for $N u_{h r}$. However the differences for average total Nusselt numbers $\left(N u_{\text {total }}\right)$ are $1 \%$ and $1.5 \%$ for Case 1 and Case 2 respectively (Table 1 ).

\begin{tabular}{|c|c|c|c|c|}
\hline & \multicolumn{2}{|c|}{ Case 1 } & \multicolumn{2}{c|}{ Case 2 } \\
\hline $\begin{array}{c}\text { Velusa } \\
\text { my et al. }\end{array}$ & $\begin{array}{c}\text { This } \\
\text { work }\end{array}$ & $\begin{array}{c}\text { Velusa } \\
\text { my et al. }\end{array}$ & $\begin{array}{c}\text { This } \\
\text { work* }^{*}\end{array}$ \\
\hline $\begin{array}{c}N u_{h} \\
- \text { conv }\end{array}$ & 334.90 & $\begin{array}{c}345.22 \\
(3.08 \%)\end{array}$ & 326.03 & $\begin{array}{c}336.30 \\
(3.15 \%)\end{array}$ \\
\hline $\begin{array}{c}N u_{c} \\
-c o n v\end{array}$ & 339.34 & $\begin{array}{c}349.98 \\
(3.14 \%)\end{array}$ & 344.57 & $\begin{array}{c}355.89 \\
(3.29 \%)\end{array}$ \\
\hline $\begin{array}{c}N u_{h} \\
-r a d\end{array}$ & 873.58 & $\begin{array}{c}872.66 \\
(0.11 \%)\end{array}$ & 523.06 & $\begin{array}{c}522.52 \\
(0.10 \%)\end{array}$ \\
\hline $\begin{array}{c}N u_{c} \\
-r a d\end{array}$ & 869.14 & $\begin{array}{c}867.52 \\
(0.19 \%)\end{array}$ & 504.52 & $\begin{array}{c}502.89 \\
(0.32 \%)\end{array}$ \\
\hline $\begin{array}{c}N u_{t} \\
\text { otal }\end{array}$ & 1208.5 & $\begin{array}{c}1217.88 \\
(0.78 \%)\end{array}$ & 849.09 & $\begin{array}{c}858.82 \\
(1.15 \%)\end{array}$ \\
\hline
\end{tabular}

The values among parenthesis are percentage absolute differences

Table 1. Comparison of the present study with reported results by Velusamy et al., (2001) for the turbulent natural convection and surface thermal radiation in a square cavity.

\section{Results and discussion}

\subsection{Parameter of study}

The parameters used to obtain the conjugate heat transfer results for the square cavity with a semitransparent wall using a solar control film are described next. The cavity length considered in this work is the $4.0 \mathrm{~m}$. The solar radiation incoming in a normal direction over the semitransparent wall has a constant value of 750 $\mathrm{W} / \mathrm{m}^{2}$. The glass thickness was set at $6 \mathrm{~mm}$ with a selective coating film of $\mathrm{SnS}-\mathrm{Cu}_{\mathrm{x}} \mathrm{S}$ whose properties were reported by Nair et al. [1] and are shown in Table 2. The isothermal wall temperature was taken as $21^{\circ} \mathrm{C}(294 \mathrm{~K})$. The external conditions around the semitransparent wall were: the external convection coefficient was assumed constant at a value of $6.8 \mathrm{~W} / \mathrm{m}^{2} \mathrm{~K}$ corresponding to a wind velocity of $3 \mathrm{~m} / \mathrm{s}$ and the ambient temperature was fixed at a temperature of $35^{\circ} \mathrm{C}(308 \mathrm{~K})$ (warm climates). The emissivity of the semitransparent wall without the solar control film was set to 0.85 and when the solar control film was considered, the emissivity was assumed to 0.4 . The emissivity of the remaining walls was varied in a range: $0.1 \leq \varepsilon^{*} \leq 1.0$ 


\begin{tabular}{|c|c|c|}
\hline $\begin{array}{c}\text { Glass (6 } \\
\mathrm{mm})\end{array}$ & Film (SnS-Cuxs) & (Glass-Film) \\
\hline$\alpha_{g}^{*}=0.14$ & $A^{*}=0.64$ & $\begin{aligned} \alpha_{y s s t} & =\alpha_{g}+\alpha_{f} \\
& =0.69\end{aligned}$ \\
\hline$\tau_{g}^{*}=0.78$ & $\mathrm{~T}^{*}=0.20$ & $\begin{array}{c}\tau_{\text {syst }}^{*}=1-\alpha_{\text {sist }}^{*}- \\
\rho_{\text {sist }}=0.15\end{array}$ \\
\hline$\rho_{g}^{*}=0.08$ & $\mathrm{R}^{*}=0.16$ & $\begin{array}{c}\rho_{\text {syst }}^{*}=\mathrm{R}^{\star} / 100 \\
=0.16\end{array}$ \\
\hline$\varepsilon_{g}^{*}=0.85$ & $\varepsilon_{f}^{*}=0.40$ & \\
\hline $\begin{array}{c}\lambda_{g}=1.4 \\
\mathrm{~W} / \mathrm{mK}\end{array}$ & $\begin{aligned} \alpha_{f}^{*}= & \left(1-\alpha_{g}^{*}\right) \mathrm{A}^{*} / 100 \\
= & 0.55\end{aligned}$ & \\
\hline $\begin{array}{c}C p_{g}=750 \\
\mathrm{~J} / \mathrm{kgK}\end{array}$ & $\begin{array}{c}\tau_{f}^{*}=\tau_{\text {sist }}^{*} / \tau_{g}^{*}= \\
0.19\end{array}$ & \\
\hline $\begin{array}{c}\rho_{g}=2500 \\
\mathrm{~kg} / \mathrm{m}^{3}\end{array}$ & $\begin{aligned} \rho_{f}^{*}= & 1-\tau_{f}^{*}-\alpha_{f}^{*}= \\
& 0.26\end{aligned}$ & \\
\hline
\end{tabular}

Table 2. Optical and thermophysical properties of glass and $\mathrm{SnS}-\mathrm{Cu} \mathrm{S}$ solar control coating.

The results of this analysis are presented as isotherms and average air temperatures as a function of the surface emissivities. As well, effective heat gain inside the cavity for the case of the semitransparent wall with control solar film (case A) and without control solar film (case B) are presented.

\subsection{Isothermals and average air temperature in the cavity}

Figure 4 shows the isothermals inside the cavity for Case A and Case B, for emissivity values of $0.1,0.5$ and 0.9 . In general, stratification occurs in most of the cavity for all cases. Results for an (opaque wall) emissivity of 0.1 show that, for case $B$, the temperatures are higher than those for case A. It can be seen that at $2 \mathrm{~m}$ height case $A$ presents an isothermal of $320 \mathrm{~K}$ and for case $\mathrm{B}$ of $322.5 \mathrm{~K}$. For an emissivity value of 0.5 results show that the values of the isothermals are slightly higher in case A than in case B. Significant differences for the isothermals values for an emissivity of 0.9 are observed; in case A isothermals are shown within an interval from 305 to $315 \mathrm{~K}$ and in case $\mathrm{B}$ from 300 to $305 \mathrm{~K}$. It can be noted that average air temperature inside the cavity is higher for case A. Summarizing, as observed from Figure 4, this results indicated that there is an interval of wall-emissivity values for which the temperatures inside the cavity are lower for case A when compared to case B and vice-versa.

Figure 5 shows the average air temperature inside the cavity as a function of the emissivity values. In general, for both cases, the average air temperature behavior is almost linear and it diminishes as the wall emissivity value increases. This increment on the average temperature as the emissivity increases can be explained as follows: by the Kirchoff law approximation the emissivity becomes approximately equal to the wall absortivity $\left(\varepsilon^{*} \approx \alpha^{*}\right)$, then if the cavity opaque walls absorb less energy (emissivity diminishes $\approx$ absortivity diminishes), more energy will be given in to the cavity fluid by any of the energy transport phenomenon and as a consequence temperature will increase. For case $A$ the average temperature is between the interval 51.7 to $37.2^{\circ} \mathrm{C}$ and for case $B$ the interval is 55.4 to $28.3^{\circ} \mathrm{C}$. The average temperature values for both cases intercept on an emissivity value of $\cong 0.46$, below this emissivity value average temperature for case $A$ is lower than for case B. So, is in this emissivity interval $\left(\varepsilon^{*} \leq\right.$ 0.46 ) where the use of the $\mathrm{SnS} . \mathrm{Cu}_{\mathrm{x}} \mathrm{S}$ solar control film is recommendable to be used rather than the window glass without it. This result allows us to conclude that there might be a range for each configuration conformed by the window glass and the solar control film.

Table 3 shows the average temperature inside the cavity with a semi-transparent wall for cases $A$ and $B$ that correspond to all the emissivity values considered for this study. It can be seen that for all the emissivity values the semitransparent wall temperature is higher for case $\mathrm{A}$ than for case $B$, this is due to the semitransparent wall configuration of case $A$ has a much higher absortivity value due to the solar control film (see Table 2). In both cases, the semi-transparent wall temperature increases when the emissivity on the remaining walls diminishes; physically the result makes sense, due to the assumption that when the emissivity on the opaque walls diminishes so too does the absortivity reducing radiation exchange from the semi-transparent wall to the interior walls. 

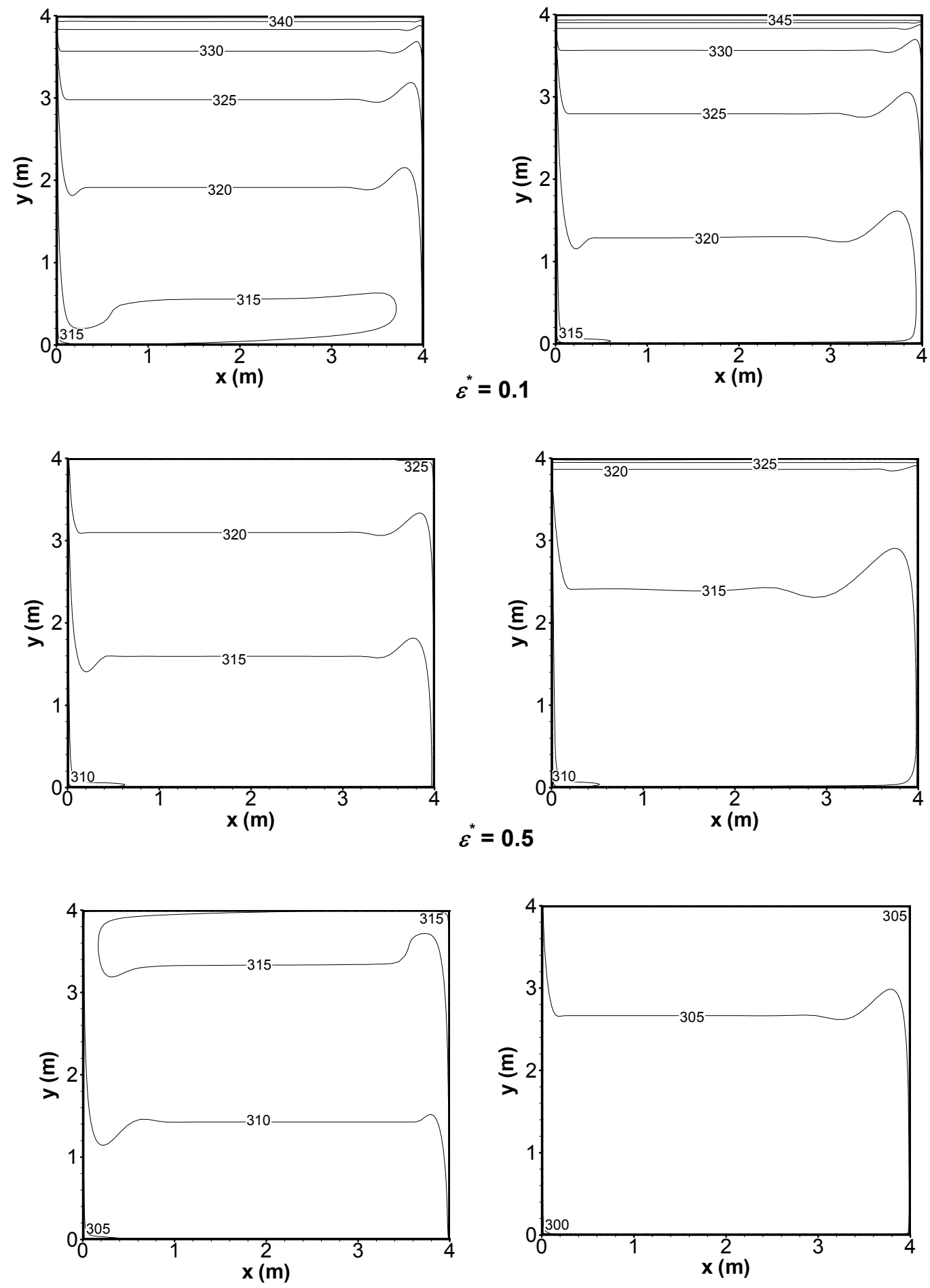

Case A

$$
\varepsilon^{*}=0.9
$$

Case B

Figure 4. Isotherms $(\mathrm{K})$ for an emissivity of $\varepsilon^{*}=0.1,0.5$ and 0.9 for case $A$ and case $B$ 


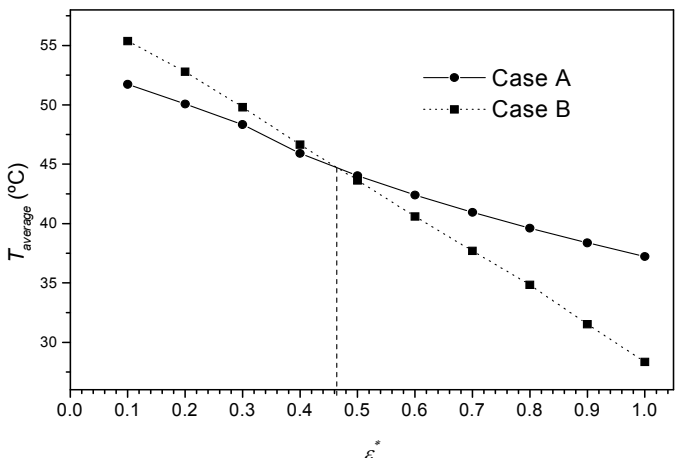

Figure 5. Average air temperature as a function of the emissivity for case $A$ and case $B$.

\begin{tabular}{|c|c|c|}
\hline \multirow{2}{*}{$\varepsilon^{*}$} & \multicolumn{2}{|c|}{$\boldsymbol{T}_{\text {g-average }}\left({ }^{\circ} \mathbf{C}\right.$ ) } \\
\cline { 2 - 3 } & $\begin{array}{c}\text { Case A } \\
\text { (with film) }\end{array}$ & $\begin{array}{c}\text { Case B } \\
\text { (without film) }\end{array}$ \\
\hline 0.1 & 68.77 & 67.47 \\
\hline 0.2 & 66.50 & 61.71 \\
\hline 0.3 & 64.91 & 57.06 \\
\hline 0.4 & 63.34 & 53.05 \\
\hline 0.5 & 62.21 & 49.59 \\
\hline 0.6 & 61.26 & 46.44 \\
\hline 0.7 & 60.45 & 43.61 \\
\hline 0.8 & 59.75 & 41.04 \\
\hline 0.9 & 59.12 & 38.53 \\
\hline 1.0 & 58.56 & 36.25 \\
\hline
\end{tabular}

Table 3. Average temperature of the interior surface of the semitransparent wall in function of the emissivity for case $A$ and case $B$.

\subsection{Total heat flux in the cavity}

On previous publications, Xamán et al. [8, 10] confusion has emerged; in order to clarify this let us take cases $A$ and $B$ with a wall emissivity of $\varepsilon^{*}=0.9$. In Table 4 , the average heat transfer fluxes of semitransparent wall for cases $A$ and $B$ are presented for $\varepsilon^{*}=0.9$. The nomenclature used is as follow: $q_{\tau}=$ transmitted heat flux through the semitransparent wall toward the interior of the cavity, $q_{\alpha}=$ absorbed heat flux by the semitransparent wall, $q_{\rho}=$ reflected heat flux to cavity outside, $q_{\text {int }}=$ inside heat flux by natural convection and thermal radiation from the semitransparent wall to the cavity, $q_{\text {out }}=$ outside heat flux by natural convection and thermal radiation from the semitransparent wall toward the outside of the cavity, $q_{\text {int }}+q_{\tau}=$ inside total heat flux, $q_{\text {out }}+q_{\rho}=$ outside total heat flux. Confusion lies mainly when evaluating results for the total heat flux inside the cavity $\left(\boldsymbol{q}_{\text {int }}+\boldsymbol{q}_{\tau}\right)$ it can be appreciated that it is lower for case A $\left(331.44 \mathrm{~W} / \mathrm{m}^{2}\right)$ than for case $B\left(646.24 \mathrm{~W} / \mathrm{m}^{2}\right)$; now, when results for the air average temperature inside the cavity are quantified, it is observed that temperature for case $A$ is higher than for case B. So, how would it be possible to get a higher average air temperature on case $A$ compared to case $B$, if for case $A$ the heat flux is lower. The answer to this possible inconsistency comes further. The isothermal wall was assumed to be an opaque wall, with an emissivity of 0.9 , is practically the cause of the increasing temperatures of air at inside when the solar control film is used (case $A$ ) regarding to the case when solar control film is not used (case B), this is explained as follows: It can be seen from Table 4 that for case $A$, the amount of total energy inside the cavity $\left(q_{\text {int }}+q_{\tau}\right)$ is $331.44 \mathrm{~W} / \mathrm{m}^{2}$ and $646.24 \mathrm{~W} / \mathrm{m}^{2}$ for case $B$, then we thought how could it be possible that higher temperatures were reached in case $A$, where the amount of energy was lower regarding to case $B$. The amount of total energy inside the cavity is made up of the radiation and convection energy $\left(q_{\text {int }}\right)$ plus the solar energy directly transmitted through the semitransparent wall $\left(q_{\tau}\right)$. In Table 4 we can observe that $q_{\text {int }}$ is higher for case $A$ regarding to case $B$ (case $A$ : 194.15 W/m², case B: $61.12 \mathrm{~W} / \mathrm{m}^{2}$ ), this result seems to be logical, as the average temperature of the semitransparent wall is higher in case $A(59.12$ $\left.{ }^{\circ} \mathrm{C}\right)$ than the one reached in case $\mathrm{B}\left(38.53{ }^{\circ} \mathrm{C}\right)$ (Table 3). For the case of $q_{\tau}$, on Table 4 it can be seen that its value is lower for case $A$ (case $A$ : $137.29 \mathrm{~W} / \mathrm{m}^{2}$, case B: $585.12 \mathrm{~W} / \mathrm{m}^{2}$ ); at this point the isothermal wall plays an important roll, due to the energy $q_{\tau}$, was considered to fall in a direct form and perpendicular to the isothermal wall. As the isothermal wall was considered to have an emissivity of 0.9 and according to Kirchoff's Law emissivity equals absortivity $\left(\varepsilon^{*}=\alpha^{*}\right)$ then, the $q_{\tau}$ energy that reached the isothermal wall in case $A$ were 137.29, from this amount 123.56 were absorbed for the isothermal wall (heat sink) and the rest of it, which is $13.73 \mathrm{~W} / \mathrm{m}^{2}$ returned to the inside of the cavity by convection or radiation, that is represented in Figure 6. Summarizing, the total effective energy inside the cavity for case $A$ is $\left(q_{\text {int }}+\left(q_{\tau}-\alpha^{*} q_{\tau}\right)\right): \quad q_{\text {int }}=194.15 \mathrm{~W} / \mathrm{m}^{2}$ plus the percentage of $q_{\tau}$ energy that was not absorbed by 
the isothermal wall $\left(13.73 \mathrm{~W} / \mathrm{m}^{2}\right)$ equals to 207.88 $\mathrm{W} / \mathrm{m}^{2}$. Regarding to case $\mathrm{B}$, the energy that reached the isothermal wall was 585.12, from which 526.61 were absorbed for the isothermal wall (heat sink) and $58.51 \mathrm{~W} / \mathrm{m}^{2}$ returned to the inside of the cavity. In the same way, the total effective energy inside the cavity for case B is $\left(q_{\text {int }}+\left(q_{\tau}-\alpha^{*} q_{\tau}\right)\right): \quad q_{\text {int }}=61.12 \mathrm{~W} / \mathrm{m}^{2}$ plus the percentage of $q_{\tau}$ energy that was not absorbed by the isothermal wall $\left(58.51 \mathrm{~W} / \mathrm{m}^{2}\right)$ equals to 119.63 $\mathrm{W} / \mathrm{m}^{2}$. Concluding, the amount of energy at the inside cavity is higher in case A $\left(207.88 \mathrm{~W} / \mathrm{m}^{2}\right)$ regarding to case $B\left(119.63 \mathrm{~W} / \mathrm{m}^{2}\right)$, for that reason temperature is higher in case $A$.

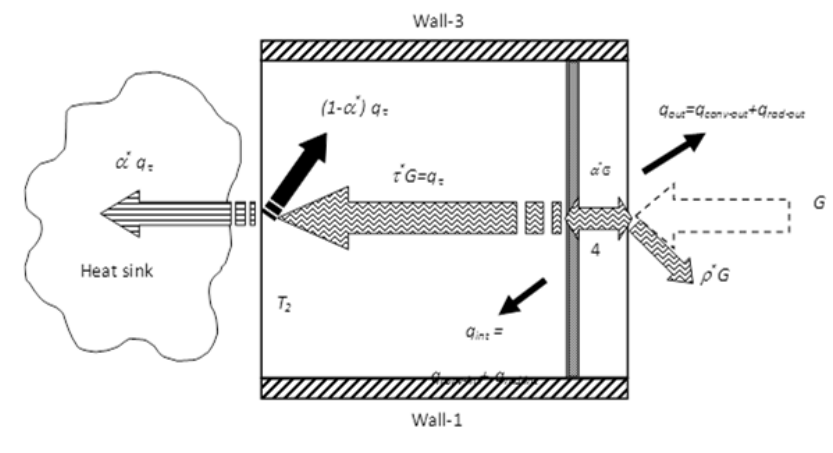

Figure 6. Schematic diagram of the total effective energy inside the cavity.

Finally, in order to show the heat gain that remains in the system consisting on the cavity and the semi-transparent wall, Figure 7 shows the total effective heat flux inside the cavity for cases $\left(q_{\text {int }}+\left(q_{\tau}-\alpha^{*} q_{\tau}\right)\right)$ A and $\mathrm{B}$ as a function of the emissivities. In this figure it can be observed that both curves intercept for an emissivity value of $\cong$ 0.46 , this value coincide with the one presented in Figure 4 for the average air temperature. It is observed that for the emissivity value interval of $\varepsilon^{*} \leq 0.46$ the total effective heat gain for case $A$ is lower than for case $B$ and for this interval the use of the solar control film under study is recommended.

An average total Nusselt numbers as a function of the emissivity for case A was obtained. Using least square regression, a correlation for the average Nusselt number for case $A$ for $0.1 \leq \varepsilon^{*} \leq 1.0$ is: $N u_{\text {total }}=806.8355 \varepsilon^{*} 0.5546$. The Nusselt number correlation shows a maximum percentage difference of $2.11 \%$ against the numerical results.

\begin{tabular}{|c|c|c|}
\hline Case & A & B \\
\hline $\boldsymbol{q}_{\tau}$ & 137.29 & 585.12 \\
\hline $\boldsymbol{q}_{\alpha}$ & 492.49 & 104.61 \\
\hline $\boldsymbol{q}_{\rho}$ & 120 & 60 \\
\hline $\boldsymbol{q}_{\text {int }}$ & 194.15 & 61.12 \\
\hline $\boldsymbol{q}_{\text {out }}$ & 298.36 & 43.49 \\
\hline $\boldsymbol{q}_{\text {int }}+\boldsymbol{q}_{\tau}$ & 331.44 & 646.24 \\
\hline $\boldsymbol{q}_{\text {out }}+\mathbf{q}_{\rho}$ & 418.36 & 103.49 \\
\hline
\end{tabular}

Table 4. Average heat fluxes $\left(\mathrm{W} / \mathrm{m}^{2}\right)$ for case $\mathrm{A}$ and $\mathrm{B}$ for $\varepsilon^{*}=0.9$.

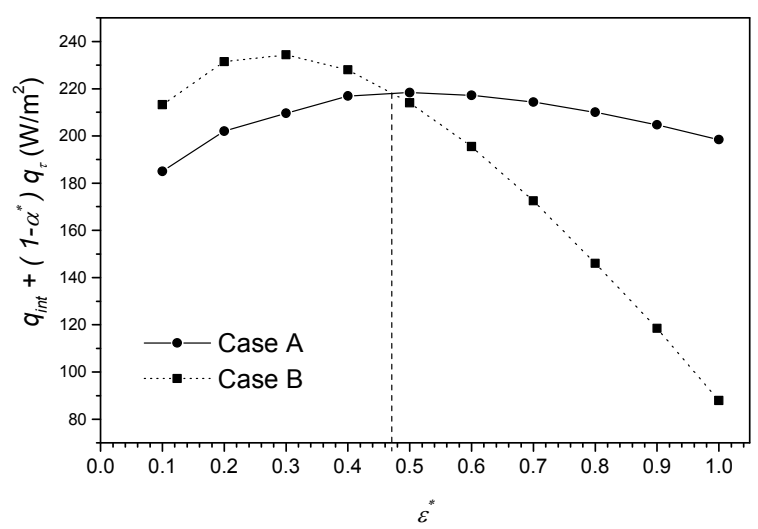

Figure 7. Total effective energy inside the cavity as a function of the emissivity for case A and case B.

\section{Conclusions}

This work presents a numerical study of the conjugate heat transfer in a square cavity with turbulent flow. The cavity has one vertical isothermal wall, two horizontal adiabatic walls and one vertical semitransparent wall with and without a $\mathrm{SnS}-\mathrm{Cu}_{\mathrm{x}} \mathrm{S}$ solar control film coating applied to control the solar radiation transmission.

Analysis on the isothermals as a function of the emissivity, it was found that there exists an emissivity interval for which temperatures on case $A$ are lower compared to case B and vice versa. This interval was determined from the air average temperature results and the effective energy flux inside the cavity; results on each case coincided on an emissivity interval, where the use of the solar control film $\mathrm{SnS}-\mathrm{Cu}_{\mathrm{x}} \mathrm{S}$ on the semi- 
transparent wall is recommended rather than the wall without it. This result allows us to conclude that there might be a range for one and each of the unique configurations conformed by the window glass and the solar control film. A correlation for the heat transfer as a function of the emissivity was determined.

Results from this study also let us to observe the influence on having an isothermal wall as a heat sink, which should be replaced for a heat conductive wall in future works. As future work similar studies for different solar control films should be carried out due to its optical behavior is not an only conclusive element to determine if its use would give us lower temperatures inside rooms, the selection for a solar control film should be accompanied by a thermal study.

Finally, the developed 2-D numerical model of conjugate turbulent heat transfer in a cavity with semitransparent wall was capable of studying in detail the heat transfer phenomena. This may represent an advance in the knowledge of what we can have in real rooms with a window having or not, solar control film coating.

\section{Acknowledgements}

The authors are grateful to Consejo Nacional de Ciencia y Tecnología (CONACYT) - Thematic Research Networks: Energy Sources (REDFE), whose financial support made this work possible.

\section{References}

[1] M. Nair, P. Nair, SnS-CuxS thin film combination: a desirable solar control coatings for architectural and automobile glazings. J. Physics D: Applied Physics 24 (1991) 450-453.

[2] N. Ramesh, S.P. Venkateshan, Effect of surface radiation on natural convection in a square enclosure. J. Thermophysics Heat Transfer 13 (1999) 299-301.

[3] K. Velusamy, T. Sundararajan, K. Seetharamu, Interaction effects between surface radiation and turbulent natural convection in square and rectangular enclosures. J. Heat Transfer 123 (2001) 1062-1070.
[4] Anil Kumar Sharma, K. Velusamy, C. Balaji, S.P. Venkateshan, Conjugate turbulent natural convection with surface radiation in air filled rectangular enclosures. Int. J. Heat Mass Transfer 50 (2007) 625-639.

[5] M. Behnia, J. Rizes, G. De Vahl Davis, Combined radiation and natural convection in a cavity with a transparent wall and containing a non-participant fluid. Int. J. Numerical Methods Fluids 10 (1990) 305-325.

[6] G. Álvarez, C. Estrada, Numerical heat transfer in a cavity with a solar control coating deposited to a vertical semitransparent wall. Int. J. Numerical Methods Fluids 34

(2000)

585-607.

[7] J. Xamán, G. Álvarez, Effect of heat conduction of SnS-CuxS solar control coated semitransparent wall on turbulent natural convection in a square cavity. Numerical Heat Transfer Part A 50 (2006) 79-98.

[8] J. Xamán, J. Arce, G. Álvarez, Y. Chávez, Laminar and turbulent natural convection combined with surface thermal radiation in a square cavity with a glass wall. Int. J. Thermal Sciences 47 (2008) 1630-1638.

[9] J. Xamán, G. Álvarez, J.F. Hinojosa, J. Flores, Conjugate turbulent heat transfer in a cavity with a solar control coating deposited to a vertical semitransparent wall. Int. J. Heat Fluid Flow 30 (2009) 237-248.

[10] R. Henkes, F. Van-Der-Vlugt, C. Hoogendoorn, Natural-convection flow in a square cavity calculated with low-Reynolds-number turbulence models. Int. J. Heat Mass Transfer 34 (1991) 377-388.

[11] J. Van Doormaal, G. Raithby, Enhancements of the SIMPLE method for predicting incompressible fluid flow. Numerical Heat Transfer 7 (1984) 147-163.

[12] J. Xamán, G. Álvarez, L. Lira, C. Estrada, Numerical study of heat transfer by laminar and turbulent natural convection in tall cavities of facade elements. Energy $\begin{array}{llll}\text { Buildings } & 37 & \text { (2005) }\end{array}$

[13] J. Xamán, J.F. Hinojosa, J. Flores, R. Cabanillas, Effect of the surface thermal radiation on turbulent natural convection in tall cavities of façade elements. Heat Mass Transfer, 45 (2008) 177-185.

[14] R. Henkes, C, Hoogendoorn, Comparison exercise for computations of turbulent natural convection in enclosures. Numerical Heat Transfer, Part B, 28 (1995) 59-78. 
[15] F. Ampofo, T. Karayiannis, Experimental benchmark data for turbulent natural convection in an air filled square cavity. Int. J. Heat Mass Transfer 46 (2003) 3551-3572.

[16] C.D. Pérez-Segarra, A. Oliva, M. Costa, F. Escanes, Numerical experiments in turbulent natural and mixed convection in internal flows. Int. J. Num. Meth. Heat
Fluid
Flow
5
(1995)
13-33.

[17] P.L. Betts, I.H. Bokhari, Experiments on turbulent natural convection in an enclosed tall cavity. Int. J. Heat Fluid Flow 21 (2000) 675-683.

[18] S. Pope, 2000. Turbulent Flows, Cambridge University Press, UK.

[19] M. Modest, 1993. Radiative heat transfer, McGrawHill, New York.

[20] S. Patankar, 1980. Numerical Heat Transfer and Fluid Flow, Hemisphere Publishing Corporation, Washington DC.

[21] S. Kwon, Y. Kwon, J. Park, Numerical study of combined natural convection and radiation in a rectangular enclosure with a transparent window on the center region of right wall. In: 6th International Symposium on Transport Phenomena in Thermal Engineering, Seoul, Korea, 1993, pp. 299-304. 